\title{
Acceptance of Cosmetic Surgery among Hungarian Women in a Global Context: the Hungarian Version of the Acceptance of Cosmetic Surgery Scale (ACSS)
}

\author{
Norbert Meskó ${ }^{1}$ (B) - András Láng ${ }^{1}$ \\ Published online: 10 November 2019 \\ (C) The Author(s) 2019
}

\begin{abstract}
In recent years, the popularity of surgical cosmetic procedures has dramatically increased in the Western world. The Acceptance of Cosmetic Surgery Scale (ACSS) provides a measure of psychological acceptance of cosmetic surgery. The original instrument (ACSS) contains three subscales (Interpersonal, Social, and Consider). Since its publication, the ACSS has been adapted for many languages. The primary objective of the present study was to develop the Hungarian version of the ACSS. Furthermore, focus was laid on whether the original factor structure could be replicated with a Hungarian sample despite expectable cultural differences from other national samples. To obtain cross-culturally comparable data, the same scales were used for psychometric analysis as those used in the development of the original ACSS and its various national versions. The Hungarian sample included 482 female participants aged between 18 and 68 years $(M=29.02, \mathrm{SD}=10.71)$, who completed a questionnaire battery. Validity of the Hungarian version was tested with the following measures: the Rosenberg Self-Esteem Scale (RSES), the Sociocultural Attitudes Towards Appearance Questionnaire-3 (SATAQ-3), the Satisfaction with Life Scale (SWLS), the Body Appreciation Scale (BAS), and the Photographic Figure Rating Scale (PFRS) developed for women. The results show that the obtained Hungarian version of the ACSS is a reliable and valid measure, which enables researchers in the field to study Hungarian samples. Furthermore, the factor structure of the Hungarian scale is identical with that of the original ACSS, which enables reliable cross-cultural comparisons. For these reasons, the authors expect that the Hungarian ACSS will stimulate more in-depth quantitative research on attitudes towards cosmetic surgery within the Hungarian context, and it will also contribute to a better understanding of acceptance of cosmetic surgery from a cross-cultural perspective.
\end{abstract}

Keywords Acceptance of cosmetic surgery scale · Hungarian version · International comparison

\section{Theoretical Background}

\section{Cosmetic Procedures}

Khoo (2009) defines cosmetic procedures as elective surgical and non-surgical procedures aimed at modifying physical appearance or certain physical features in order to enhance clients' attractiveness. There are two types of cosmetic

Electronic supplementary material The online version of this article (https://doi.org/10.1007/s12144-019-00519-z) contains supplementary material, which is available to authorized users.

Norbert Meskó

meskonorbert@me.com

1 Institute of Psychology, University of Pécs, Ifjúság útja 6, Pécs H-7624, Hungary procedures, namely, invasive and minimally-invasive procedures. Invasive procedures change the physical structure of the body by means of surgery. These include procedures such as breast augmentation, facelift and liposuction. Minimallyinvasive procedures are highly popular, since they involve less drastic interventions and lower risk. These procedures include chemical peel, microdermabrasion and soft tissue filler injections (Ahn et al. 2013; Ajitha and Sivakumar 2017).

North America and Europe witnessed a dramatic increase in cosmetic surgeries over the past one and a half decades (e.g. Dutta 2008; Sarwer et al. 2007; Rohrich, 2003). According to the most recent annual report published by the American Society of Plastic Surgeons (ASPS 2018), 15,909,931 minimally-invasive cosmetic procedures (e.g. Botox injections, chemical peels, laser skin resurfacing) were performed in 2018, which means an increase of $226 \%$ compared to 2000. The overall picture comprises diverse tendencies, since certain surgical cosmetic procedures decreased in number. For 
example, the number of eyelid surgeries (blepharoplasty) decreased by $37 \%$ and that of nose reshaping surgeries (rhinoplasty) decreased by $45 \%$ between 2000 and 2018. At the same time, the number of breast augmentations (augmentation mammaplasty) increased by $48 \%$ and the number of lower body lifts by $4295 \%$ over the past 18 years. At a global level, cosmetic surgeries are following an increasing tendency.

Sarwer et al. (2007) attributes this tendency to several factors such as technological advances in cosmetic surgery, lower prices, higher incomes, and the growing importance of physical appearance. Moreover, as Henderson-King and HendersonKing (2005) point out, even people who do not particularly search for information on cosmetic surgery are increasingly exposed to such contents due to online social networks. Cosmetic surgery is now a common subject in the media: advertisements promise increased attractiveness and success, magazines report on the latest advances in surgical procedures, and reality shows on television focus on participants' physical transformation. The effect is likely to be further augmented by news on celebrities' cosmetic surgeries in the media, since the acceptance of cosmetic surgery has been found to be related to celebrity worship (Ching and Xu 2019; Swami 2009b).

\section{Measuring Acceptance of Cosmetic Surgery}

The increasing popularity of cosmetic surgery has been accompanied by a relatively large number of empirical studies focusing on the psychological aspects of cosmetic surgery. The available findings clearly show that one of the most important factors influencing one's decision on cosmetic surgery is one's gender. Women as compared to men are more likely to report a need for various cosmetic procedures (Brown et al. 2007). An underlying driver of this need (i.e. women's striving to enhance their physical attractiveness and sex appeal) may be social and cultural pressure. Brown and colleagues (Brown et al. 2007) found that low self-esteem related to physical appearance was associated with greater probability of applying for cosmetic surgery. Swami and colleagues (Swami et al. 2008a) point out that media exposure possibly mediates between gender and the probability of cosmetic surgery. Other studies also found that media exposure positively influenced women's acceptance of cosmetic surgery (e.g. Ashikali et al. 2017a; Ashikali et al. 2017b; Slevec and Tiggemann 2010).

Sarwer and colleagues (Sarwer et al. 2005) reported that female university students generally expressed a positive attitude towards cosmetic surgery, which they considered as a means of improving physical appearance. However, as Henderson-King and Henderson-King (2005) point out, attitudes towards cosmetic surgery may be more complex. Namely, one may accept that others want to enhance their physical attractiveness by cosmetic surgery while having no personal interest whatsoever in undergoing a cosmetic procedure. This distinction led to the need for an instrument measuring different aspects of the acceptance of cosmetic surgery. The 15-item Acceptance of Cosmetic Surgery Scale (ACSS) developed by Henderson-King and Henderson-King (2005) provides measures of the following three factors of acceptance of cosmetic surgery: (1) The Intrapersonal factor assesses the personal benefits expected from cosmetic surgery (e.g. enhancing one's satisfaction with one's appearance). (2) The Social factor taps the social motives underlying the decision on cosmetic surgery (e.g. enhancing one's attractiveness to meet one's partner's needs) (3) The Consider factor measures the considerations influencing how likely one is to apply for cosmetic surgery (e.g. wound healing complications, pain, infections). The authors tested the scale in a series of four studies involving samples of university students and found that the instrument had high internal consistency, good testretest reliability and good convergent validity.

\section{The Psychological Aspects of Acceptance of Cosmetic Surgery}

The initial studies using the ACSS revealed, for example, that women and older respondents showed a more positive attitude on the Intrapersonal subscale than men and younger respondents, and older respondents expressed a more positive attitude on the Social subscale (Henderson-King and Henderson-King 2005). Age was a positive predictor of women's willingness to consider having cosmetic surgery, whereas no such relationship was found among men. Another early study revealed a positive relationship between the acceptance of cosmetic surgery and body image dissatisfaction among female university students: participants with higher levels of body image dissatisfaction or disturbance showed higher levels of acceptance of cosmetic surgery (Cash et al. 2005). A more recent study assessed the impact of body image satisfaction, age-related anxiety, and media exposure on attitudes towards cosmetic surgery among women aged 35 to 55 years, and the authors found that media effects had the strongest influence on middle-aged women's attitudes (Slevec and Tiggemann 2010).

The next wave of research revealed the demographic, psychosocial and individual factors influencing the consideration of having cosmetic surgery. For example, various studies on the importance of demographic variables consistently found that women were more likely than men to consider having cosmetic surgery (e.g. Brown et al. 2007; Swami et al. 2008b; Swami et al. 2009a). This finding is further corroborated by the fact that the overwhelming majority of cosmetic surgeons' clients are women, and most studies on cosmetic surgery are likewise targeted at them. A study conducted with British university students found that Caucasian women forming the ethnic majority of students reported lower body appreciation and lower self-esteem as compared to South Asian and Afro-Caribbean women (Swami et al. 2012b). Furthermore, Caucasians showed higher acceptance of 
cosmetic surgery than their ethnic minority peers even when controlling for body appreciation, self-esteem, age, and body mass index (BMI).

Most related studies focused on the relationship between the likelihood of considering cosmetic surgery and individual psychological variables. Several authors reported a positive relationship between acceptance of cosmetic surgery and body image dissatisfaction (Crerand et al. 2006; Slevec and Tiggemann 2010; Swami 2009). Another line of research revealed a positive relationship between willingness to invest in physical appearance and acceptance of cosmetic surgery (Delinsky 2005; Sarwer et al. 2005). In addition, the consideration of having cosmetic surgery was found to be positively associated with social conformity (Swami 2009), with sensitivity to social rejection related to physical appearance (Park et al. 2009), and with the Big Five personality factors (Swami et al. 2009a).

Among psychosocial factors, the context of one's intimate partner relationship may have essential importance in one's acceptance of cosmetic surgery (Swami and Mammadova 2012). This is an important field of research particularly because attractiveness is a crucial factor in romantic relationships. Since women's attractiveness was consistently found in all studied cultures to have more importance in mate choice than men's attractiveness (Buss 1989), some authors recently attempted to explain women's increased willingness to consider cosmetic surgery in an evolutionary framework. Findings of three studies conducted by Bradshaw et al. (2019) confirm that expensive appearance-enhancing procedures such as cosmetic surgery may be part of a short-term mate choice strategy. The first study demonstrated that women who showed a preference for investing in short-term relationships expressed a more positive attitude towards expensive appearance-enhancing procedures (e.g. cosmetic surgery) as opposed to relatively low-cost procedures (e.g. makeup). The second and third studies revealed that both women and men used the information they received about female targets' willingness to have cosmetic surgery to predict the targets' shortterm investments in mate choice. Another study found that the consideration of having cosmetic surgery may be part of a mate retention strategy (Atari et al. 2017). Given that women's mate value is more closely related to physical attractiveness than men's (Puts 2016), it is not a surprise that women are more interested in appearance-enhancing procedures (e.g. cosmetic surgery). Since enhancing physical attractiveness may be an adequate female strategy either to deter same-sex rivals (intrasexual competition) or to retain a sexual partner (intersexual competition), women are willing to try various ways to improve their physical appearance. Atari and colleagues (Atari et al. 2017) found that Tehran (Iranian) women considered having cosmetic surgery because their attractivenessenhancing behaviour was part of a benefit-provisioning strategy to retain a long-term mate.

\section{International Adaptations of the ACSS}

In the Western world, media contents play a particular role in promoting the Western feminine beauty ideal (Calogero et al. 2007). Increasing global penetration of the Western media has been accompanied by a rapid growth in global popularity of cosmetic surgery. At the same time, a need for psychological research on cosmetic surgery, body image and self-esteem seems to have developed in various cultures. Since the initial studies were conducted in the English-speaking world (mostly in North America and in the United Kingdom), the ACSS has been translated into several languages, and several studies using these adaptations have been carried out with local samples over the past decade. The original English version of the scale has been adapted for languages such as Malay (Swami 2010), Portuguese (Brazilian adaptation; Swami et al. 2011c), Korean (South Korean adaptation; Swami et al. 2012a), Italian (Stefanile et al. 2014), Serbian (Jovic et al. 2017), Turkish (Karaca et al. 2017) and Persian (Iranian adaptation; Dehghan Manshadi et al. 2017).

However, the various national versions show diverse cultural patterns. More specifically, the original three-factor structure (Intrapersonal, Social, Consider) has only been replicated in countries whose culture is relatively close to the Western culture. Such countries are Brazil (Swami et al. 2011c) and Italy (Stefanile et al. 2014), where exploratory factor analyses conducted on the respective national versions of the ACSS revealed the same three-factor structure as that obtained for the original English version.

By contrast, various two-factor structures were obtained in Eastern countries, whose societies and cultures are essentially different from those of the Western world. One such country is Iran, where one factor of the national version corresponded to the original Intrapersonal factor, while the other factor was a compound of the Consider and Social factors (Dehghan Manshadi et al. 2017). The author of the Malay version of the ACSS also revealed two factors, but both were compounds rather than replications of the original factors (Swami 2010). The first factor partly corresponded to the Consider factor of the original ACSS, while the second factor included items of the Interpersonal and Consider factors. In sum, the factor structures of the Iranian and Malay versions are essentially different from that of the original ACSS as well as from each other. The South Korean adaptation did not replicate the original three-factor structure either, and not even a two-factor solution showed adequate fit indices, therefore one single scale was constructed, which only provides a global measure of acceptance of cosmetic surgery (Swami and Mammadova 2012). These findings are consistent with those showing that measures of body image developed with Western samples were not replicable with non-Western respondents (Swami and Barron 2018). 
One possible reason for the structural differences between the Western and Eastern versions of the ACSS lies in the different ways of thinking characteristic to Western and Eastern cultures (Swami 2010). Women in Eastern collectivistic cultures probably do not make a distinction between external and internal reasons for having cosmetic surgery, and social influence and individual decision-making processes are equally important factors of the acceptance of cosmetic surgery. Furthermore, women's individual and social motives are probably much more clearly distinguished in the Western world than in Eastern cultures. Thus, for example, North American, Brazilian and Italian women are more likely to explain their interest in cosmetic surgery by internal reasons (e.g. personal feelings about one's own body) than by external reasons (e.g. others' expectations or suggestions; Swami et al. 2012a).

\section{Cosmetic Surgery in Hungary}

While the prevalence of plastic surgery has dramatically increased in America (ASPS 2018; ISAPS 2017), and Western Europe over the past one and a half decades, the publicity of cosmetic surgery in Hungary provides an incomplete picture of the local trends. On one hand, a large number of public and private cosmetic surgery clinics are operated in large Hungarian towns, which are advertised on the Internet (e.g. Budapest Plastic Surgery Institute 2019). On the other hand, however, no information is available on the prevalence of cosmetic surgery in Hungary, since the relevant national laws do not require clinics to keep statistical records of such procedures. Therefore only indirect information is available on the growth rate of this surgical specialty in Hungary and on its relative growth at a global level. Reuters reported that Hungary had the highest rate of plastic surgeries per capita in 2012 (Park 2012). In the same vein, an OECD report revealed that Hungary was one of the most popular health tourism destinations in terms of dental services as well as plastic surgery (Lunt et al. 2011).

Hungarian cosmetic surgeons have their own interest organization (Hungarian Plastic Reconstructive and Aesthetic Surgery Association), which holds a professional conference annually. The association was founded in 1959 (Mészáros 2007), and it joined the Visegrad Plastic Surgery Society in March 2019, which was established in collaboration with professional societies in the other three countries of the Visegrad Group (the Czech Republic, Slovakia and Poland). In addition, the increased foreign demand for health tourism in Hungary suggests that the country is one of the most popular destinations for Western people who choose to have plastic surgery. "Modern clinics, short waiting time, well-educated doctors, who speak foreign languages, travel attractions, lower costs of treatment attract guests from abroad. Hungary is called 'the paradise of low prices'. The costs of medical services in Hungary are often 60 to $80 \%$ lower than in West European countries and in the United States. Hungary is an appreciated medical tourism destination for patients from France, Italy, Belgium, Denmark, Germany, Russia, Scandinavia, Switzerland and the UK. In recent years, more and more patients arrive from Asian and Middle Eastern countries and from overseas as well" (Belenyesi 2018).

Considering the popularity of Hungary as a health tourism destination, it is quite perplexing that no psychological study has yet examined the motivation for cosmetic surgery in the Hungarian population.

\section{Research Aims}

In consistence with the considerations discussed in the theoretical introduction, the present study had two interrelated aims. First, the study was aimed at developing and validating the Hungarian version of the Acceptance of Cosmetic Surgery Scale. Second, the study was aimed at establishing whether the Hungarian construct would show a structure similar to its Western (e.g. American: Henderson-King and HendersonKing 2005; Brazilian: Swami et al. 2011b; Italian: Stefanile et al. 2014), Eastern (e.g. Malay: Swami 2010; Iranian: Dehghan Manshadi et al. 2017) or South Korean counterpart (Swami et al. 2012b), which comprised three, two and one factors, respectively. The Hungarian scale was expected to replicate the original three-factor structure due to the characteristics of the Hungarian language and culture. Since women are the primary users of cosmetic surgery worldwide $(86.2 \%)$ (ISAPS 2017), and there are only females as respondents in many psychological research related to the acceptance of cosmetic surgery (e.g. Jung and Hwang 2016; Nicolas and Welling 2017; Swami 2010), the present study also adopted this sampling method. This was justified by the everyday observation that advertisements for cosmetic surgery in Hungary were more frequently targeted at women than at men, therefore female respondents were expected to more readily respond to related questions.

\section{Method}

\section{Procedure and Participants}

The Hungarian versions of the ACSS and PFRS were initially developed using the standard back-translation technique (Brislin 1980). Specifically, the authors first translated the ACSS scales and the instructions into Hungarian, and these versions were then translated back into English by an independent translator unaffiliated with the study. The two translators then resolved minor discrepancies that emerged during the back-translation process. 
According to Swami and Barron (2018) it is advisable to test the understanding of the questionnaire before collecting the data. Since we met this recommendation only after the data was collected, we were only able to test the questionnaire afterwards. For this validation study, 89 women evaluated the comprehensibility of the final version of the ACSS' Hungarian version. Participants had 20.81 years of age on average $(S D=3.05$, from 18 to 30 years). Using a 5-point Likert scale, for each of the fifteen items they rated how much they understood the content of the item ( $1=\mathrm{I}$ didn't understand at all; $5=\mathrm{I}$ completely understood). Means and standard deviations of the evaluations and comparison with good comprehension (4) are shown in Table 1. According to the results of one sample t-tests, each of the fifteen items were comprehensible better than good.

482 women participated in our study. Participants had a mean age of 29.02 years ( $S D=10.71$, range: 18 to 68$)$ and a mean self-reported BMI of $22.82 \mathrm{~kg} / \mathrm{m} 2(S D=4.23)$. Participants were recruited from Hungarian social networking sites and popular blogs on women's health, and they filled out the questionnaires online via Survey Monkey. Each participant gave informed consent and no participant was rewarded for participating. In terms of educational qualifications, $0.8 \%$ had completed primary education, $42.5 \%$ had completed secondary education, $56.6 \%$ had an undergraduate degree or specialist diploma. $49.6 \%$ of participants reported that they were currently undergraduate students. This study received ethical approval from the United Ethical Review Committee for Research in Psychology (Ref. No. 2018/20).

Table 1 Evaluation of comprehensibility for the Hungarian version of ACSS; means, standard deviations, and results of one-sample t-test $(n=$ 89)

\begin{tabular}{lllll}
\hline Item & $M$ & $S D$ & \multicolumn{2}{l}{ Test value $=4$} \\
\cline { 3 - 5 } & & & $\mathrm{t}_{(88)}$ & $p$ \\
\hline 01 & 4.75 & .61 & 11.675 & $<.001$ \\
02 & 4.90 & .43 & 19.832 & $<.001$ \\
03 & 4.84 & .47 & 16.761 & $<.001$ \\
04 & 4.72 & .62 & 10.918 & $<.001$ \\
05 & 4.51 & .81 & 5.863 & $<.001$ \\
06 & 4.89 & .35 & 23.819 & $<.001$ \\
07 & 4.78 & .54 & 13.586 & $<.001$ \\
08 & 4.87 & .46 & 17.858 & $<.001$ \\
09 & 4.89 & .38 & 21.892 & $<.001$ \\
10 & 4.99 & .11 & 88.000 & $<.001$ \\
11 & 4.87 & .44 & 16.761 & $<.001$ \\
12 & 4.91 & .32 & 26.438 & $<.001$ \\
13 & 4.84 & .52 & 15.288 & $<.001$ \\
14 & 4.58 & .78 & 7.061 & $<.001$ \\
15 & 4.83 & .46 & 17.121 & $<.001$ \\
\hline
\end{tabular}

\section{Materials}

Acceptance of Cosmetic Surgery Scale (ACSS; HendersonKing and Henderson-King 2005). The ACSS is a 15-item scale that, has been shown to consist of three subscales in Western populations, namely, Intrapersonal (five items measuring attitudes related to the self-oriented benefits of cosmetic surgery), Social (five items measuring social motivations for having cosmetic surgery), and Consider (five items measuring the likelihood that a participant would consider having cosmetic surgery). Items are rated on a 7-point scale $(1=$ Strongly disagree, $7=$ Strongly agree) and previous work has shown that the ACSS has high internal consistency, good test-retest reliability after 3 weeks, and good convergent and divergent reliability in Western samples (e.g., HendersonKing and Henderson-King 2005).

Photographic Figure Rating Scale (PFRS; Swami et al. 2008a). The PFRS consists of 10 greyscale photographic images of real women in front view, representing the full range of BMI categories. Participants were asked to rate the figure that most closely matched their own body and the figure that they would most like to possess $(1=$ Figure with the lowest BMI, $10=$ Figure with the highest BMI). A measure of ideal-actual weight discrepancy was computed as the difference between unsigned (absolute), current and ideal ratings. Previous work has shown that the PFRS retains cross-cultural validity (Swami et al. 2011b) and that scores derived from the scale have high construct validity, good test-retest reliability after three weeks, and good construct validity (Swami et al. 2008a; Swami et al. 2011c).

Body Appreciation Scale (BAS; Avalos et al. 2005; Hungarian adaptation: Béres et al. 2013). The BAS is a 13item measure of positive body image, in which items are rated on a 5 -point scale ( $1=$ Never, $5=$ Always). In Western and Hungarian samples, the BAS has been shown to have a onedimensional structure, and good discriminant, construct, and incremental validities (e.g. Avalos et al. 2005; Béres et al. 2013). Cronbach's $\alpha$ for the BAS in the present study was .92 .

Sociocultural Attitude Toward Appearance Questionnaire3 (SATAQ-3; Thompson et al. 2004; Hungarian adaptation: Czeglédi et al. 2015). The SATAQ-3 is a 30 -item scale measuring the multi-dimensional impact of sociocultural factors on body image. Items are rated on a 5 -point scale $(1=$ Strongly disagree, $5=$ Strongly agree). The scale has been shown to consist of four internally consistent factors in Western and Hungarian samples (e.g. Thompson et al. 2004; Czeglédi et al. 2015). Cronbach's $\alpha$ values for these four factors in the present study were as follows: Information: .90; Internalization-General: .86; Pressures: .93; InternalizationAthlete: .86.

Rosenberg's Self-Esteem Scale (RSES; Rosenberg 1965; Hungarian adaptation: Sallay et al. 2014). The RSES is a 10item scale that measures a global sense of self-worth. Items are 
rated on a 4-point scale $(1=$ Strongly disagree, $4=$ Strongly agree). Scores on the RSES have been shown to have high internal consistency and good convergent validity in Western and Hungarian populations (Rosenberg 1965; Sallay et al. 2014; Martos et al. 2014). Cronbach's $\alpha$ for the RSES in the present study was .90 .

Satisfaction With Life Scale (SWLS; Diener et al. 1985; Hungarian adaptation: Martos et al. 2014). The SWLS is a 5 -item measure of general satisfaction with one's life, which has been shown to have a one-dimensional structure in both Western and Hungarian populations (Diener et al. 1985; Martos et al. 2014). Items are rated on a 5-point scale $(1=$ Strongly disagree, $5=$ Strongly agree). Cronbach's $\alpha$ for this scale in the present study was .81 .

Demographics Participants provided demographic data including age, ethnicity, and self-reported height and weight. The latter two variables were used to calculate participants' BMI expressed in $\mathrm{kg} / \mathrm{m} 2$.

\section{Results}

First, to test the structural reliability of the Hungarian version of the ACSS, we ran a series of Confirmatory Factor Analyses (CFAs) using AMOS 24 for Windows. We tested the fit of four different models - the one-factor model, two two-factor models, and the three-factor model. The results of CFAs are summarized in Table 2. Comparisons between Models 1 to 4 revealed that the three-factor model (Model 4) had the best fit indices. However, some fit indices for Model 4 still indicated only a moderately good fit (Hu and Bentler 1999). Therefore, we implemented twelve error covariances in Model 5. Error covariances were implemented strictly between errors of items that belonged to the same factor. The fit indices of the threefactor model (Model 5) with covariances indicated an excellent fit of the model to our data (see Table 2 and Fig. 1). Cronbach's $\alpha$ for the three subscales were as follows: Intrapersonal: .89; Social: .92; Consider: .90. HendersonKing and Henderson-King (2005) also suggest that it is adequate to compute a total acceptance score by calculating the mean of all 15 items. In the present study, Cronbach's $\alpha$ for this overall score was .95 .

Second, we calculated Pearson's correlations to test the associations between the factors of the ACSS and other measured variables including age. Results of these analyses are presented in Table 3. According to the results, the overall score and subscale scores on the ACSS were unrelated to self-esteem and BMI. ACSS scores were significantly related to age (older women showed more acceptance), satisfaction with life (less satisfied women showed more acceptance), and perceived pressure from media towards perfect body (women who felt more pressure showed more acceptance). However, these correlations were negligible in magnitude. ACSS scores were significantly and positively correlated with internalization in general and internalization of an athletic body ideal, information and body dissatisfaction. ACSS scores showed significant negative correlations with general body appreciation. These correlations were all small to medium in magnitude. Thus, women with lower appreciation of their own body, women who were more prone to internalize a media-based or athletic body ideal and to consider media as an important source of information on appearance, and women who were less satisfied with their body showed higher acceptance of cosmetic surgery than those being more appreciative of their own body, less responsive to media influence, and more satisfied with their body.

Finally, we compared the ACSS scores for the Hungarian sample to the scores for the North American (Henderson-King and Henderson-King 2005; Study 1), Italian (Stefanile et al. 2014), Brazilian (Swami et al. 2011a), Serbian (Jovic et al. 2017), Korean (Swami et al. 2012b), and Malaysian (Swami 2010) samples. According to the results of one-sample t-tests (Table 4), Hungarian women's total acceptance score showed no difference from those of North American, Brazilian, and Serbian women. Hungarian women showed more acceptance of cosmetic surgery than Italian women but less acceptance than Korean or Malaysian women.

\section{Discussion}

The first aim of the present study was to develop and validate the Hungarian version of the ACSS with a Hungarian adult sample. While some versions of the scale adapted for different languages showed diverse factor structures (Dehghan Manshadi et al. 2017; Swami 2010), the Hungarian version replicated the three-factor structure of the original English version published by Henderson-King and Henderson-King (2005). More specifically, the three subscales of the Hungarian ACSS (Intrapersonal, Social, Consider) showed adequate internal consistency (Cronbach's $\alpha>.70$ in each case; Kline 1986). Furthermore, internal consistency of the overall scale was very high, which suggests that the scale is a reliable measure of acceptance of cosmetic surgery.

The findings related to the second aim of the study show that the Hungarian ACSS has adequate convergent validity. Respondents' acceptance of cosmetic surgery was unrelated to their self-esteem and BMI. By contrast, acceptance of cosmetic surgery negatively correlated with general body appreciation and satisfaction with life, while it was positively associated with the internalization of media contents related to appearance (including all four subscales of the SATAQ-3 scale), with age, and with body image dissatisfaction. In other words, those women showed higher levels of acceptance of cosmetic 
Table 2 Fit indices for different models of ACSS

\begin{tabular}{lllllllll}
\hline Model & $x^{2}$ & df & $\chi^{2} / \mathrm{df}$ & RMSEA (90\% CI) & SRMR & NFI & CFI & AIC \\
\hline Model 1 - One-factor model & 1475.669 & 90 & 16.396 & $.179(.171-.187)$ & .087 & .757 & .767 & 1565.669 \\
Model 2 - Two-factor model (Consider + Intrapersonal/Social) & 1108.524 & 89 & 12.455 & $.154(.146-.163)$ & .081 & .817 & .829 & 1200.524 \\
Model 3 - Two-factor model (Intrapersonal + Consider/Social) & 994.297 & 89 & 11.172 & $.145(.137-.154)$ & .062 & .836 & .848 & 1086.297 \\
Model 4 - Three-factor model & 426.402 & 87 & 4.901 & $.090(.082-.099)$ & .040 & .930 & .943 & 522.402 \\
Model 5 - Three-factor model with error covariances & 139.188 & 75 & 1.856 & $.042(.031-.053)$ & .026 & .977 & .989 & 259.188 \\
\hline
\end{tabular}

surgery who were older, more dissatisfied with their body image, more willing to internalize media contents related to appearance, and less appreciative of their own body. It has to be noted that all of these correlations were low or moderate in magnitude. Nevertheless, the Hungarian ACSS showed a pattern of correlations consistent with both the theoretical assumptions and previous empirical findings suggesting that the acceptance of cosmetic surgery was positively associated with body appreciation (e.g. Swami 2009, 2010) and with the internalization of media contents related to appearance (Ashikali et al. 2017a; Henderson-King and Brooks 2009; Markey and Markey 2009).

Findings on the Hungarian ACSS offer themselves for intriguing comparisons with other national versions. These findings are perhaps the most inconsistent with the North American data (Henderson-King and Henderson-King
Fig. 1 Standardized three-factor structure of the ACSS model (Model 5)

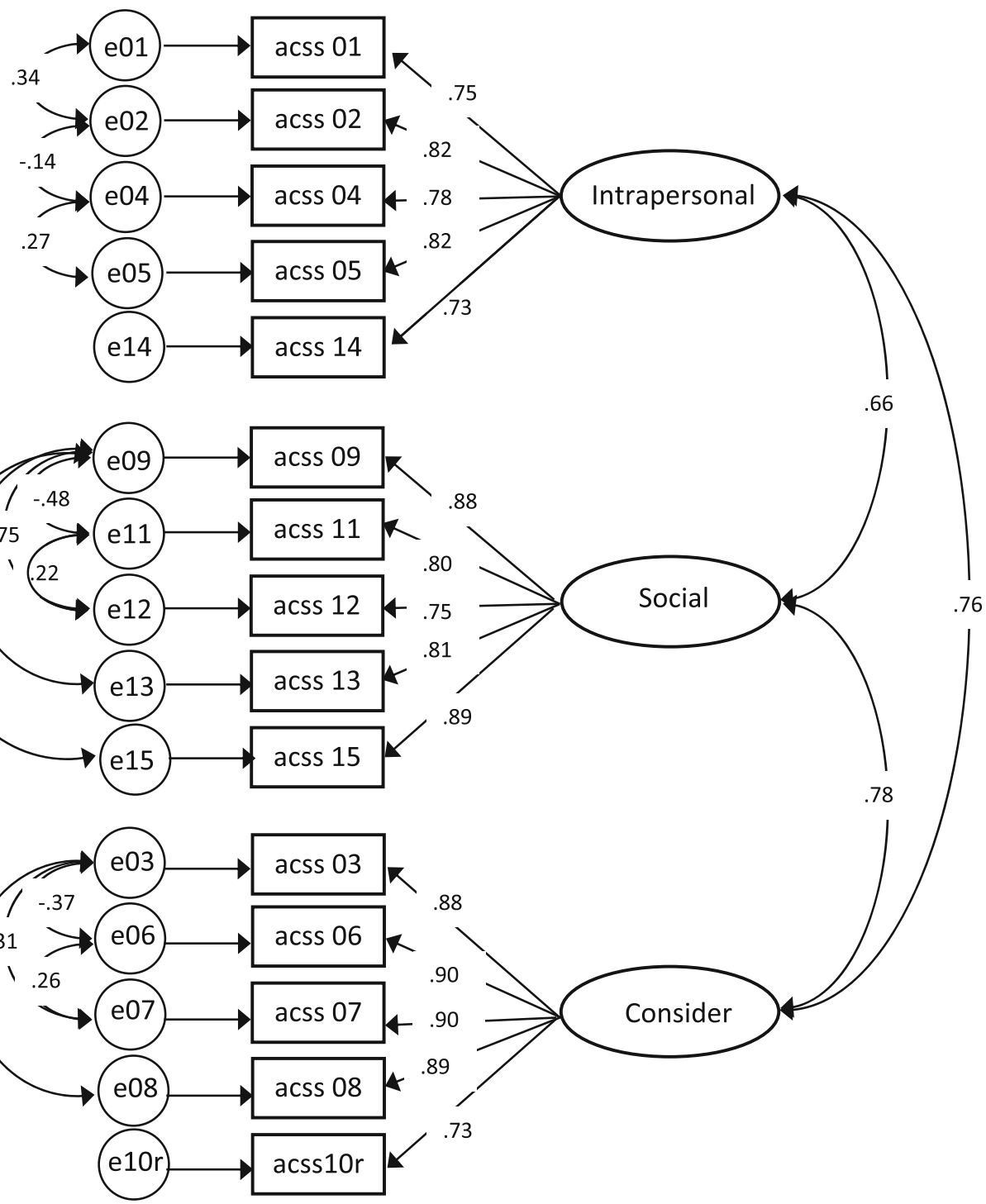









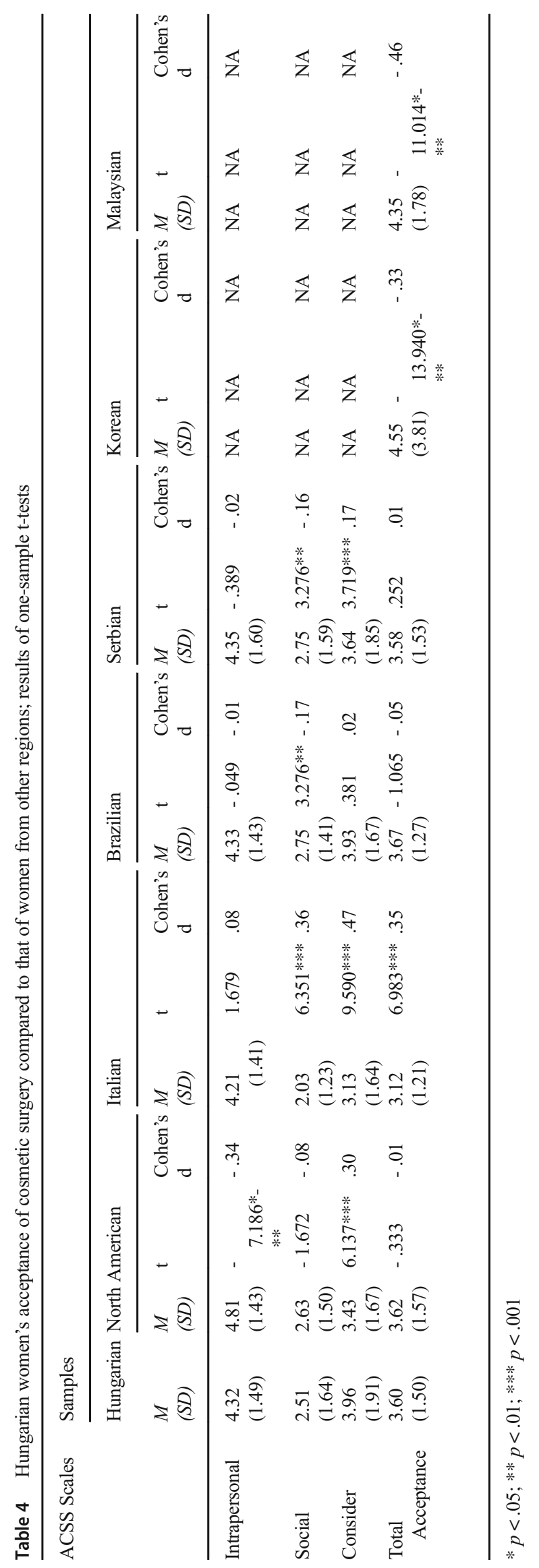


2005). Namely, while the Hungarian and North American samples showed no difference in their overall scores on the ACSS, the former scored lower on the Social subscale and higher on the Consider subscale than the latter. In comparison with the Italian data (Stefanile et al. 2014), Hungarian women reported higher levels of acceptance of cosmetic surgery on both the Social and Consider subscales but not on the Intrapersonal subscale. The Hungarian data were most consistent with the Brazilian data (Swami et al. 2011a), since a significant difference was found on only one of the three subscales: Hungarian women scored lower on the Social subscale. Since the South Korean (Swami et al. 2012b) and Malay (Swami 2010) versions comprise only one scale each, data from both countries were only compared to the overall score for the Hungarian ACSS. Hungarian women showed significantly lower levels of acceptance of cosmetic surgery than women in either of the other two countries.

In sum, the Hungarian ACSS provides reliable and valid measures of all three dimensions of acceptance of cosmetic surgery assessed by the original American scale. In consistence with its American counterpart, the Hungarian ACSS measures respondents' willingness to consider having cosmetic surgery, and the external (social) and internal (intrapersonal) psychological factors underlying their decisions. Since the Hungarian scale showed high internal consistency, and its validity was confirmed by its correlations with measures of body image and body appreciation, it will certainly provide a useful instrument for future studies with Hungarian samples.

\section{Limitations}

The validity of the findings obtained in the present study has several limitations. First, only women were involved in the study, while it is a reasonable expectation towards any study focusing on the acceptance of cosmetic surgery that data should also be collected from men. Future research should also involve male respondents. Second, no data on respondents' socioeconomic status was recorded, while it is obvious that one's financial situation potentially influences one's decision on applying for a cosmetic procedure requiring considerable financial investment. For this reason, future studies should also examine respondents' socioeconomic status. Third and finally, no data was collected on respondents' media usage and particularly on social media usage, while social media users are often exposed to contents potentially influencing their body image and thus their willingness to consider having cosmetic surgery. This factor should also be taken into account in future studies.

Acknowledgements We are thankful to Prof. Viren Swami for his comments on the first draft of this manuscript.
Funding Informaiton Open access funding provided by University of Pécs (PTE). The project has been supported by the European Union and co-financed by the European Social Fund (EFOP-3.6.1.-16-201600004 - Comprehensive Development for Implementing Smart Specialization Strategies at the University of Pécs).

\section{Compliance with Ethical Standards}

Conflict of Interest On behalf of all authors, the corresponding author states that there is no conflict of interest.

Open Access This article is distributed under the terms of the Creative Commons Attribution 4.0 International License (http:// creativecommons.org/licenses/by/4.0/), which permits unrestricted use, distribution, and reproduction in any medium, provided you give appropriate credit to the original author(s) and the source, provide a link to the Creative Commons license, and indicate if changes were made.

\section{References}

Ahn, H. Y., Wu, L., \& Taylor, R. E. (2013). Communication strategies in cosmetic surgery websites: An application of Taylor's six-segment message strategy wheel. Health Marketing Quarterly, 30(2), 97113. https://doi.org/10.1080/07359683.2013.787879.

Ajitha, S., \& Sivakumar, V. J. (2017). Understanding the effect of personal and social value on attitude and usage behavior of luxury cosmetic brands. Journal of Retailing and Consumer Services, 39, 103-113. https://doi.org/10.1016/j.jretconser.2017.07.009.

Ashikali, E. M., Dittmar, H., \& Ayers, S. (2017a). The impact of cosmetic surgery advertising on women's body image and attitudes towards cosmetic surgery. Psychology of Popular Media Culture, 6(3), 255. https://doi.org/10.1037/ppm0000099.

Ashikali, E.-M., Dittmar, H., \& Ayers, S. (2017b). The impact of cosmetic surgery advertising on Swiss women's body image and attitudes toward cosmetic surgery. Swiss Journal of Psychology, 76(1), 1321. https://doi.org/10.1024/1421-0185/a000187.

ASPS - American Society of Plastic Surgeons (2018). 2018 National Plastic Surgery Statistics: Cosmetic and Reconstructive Procedure Trends. Retrieved from https://www.plasticsurgery.org/documents/ News/Statistics/2018/plastic-surgery-statistics-report-2018.pdf on April 03, 2019.

Atari, M., Barbaro, N., Sela, Y., Shackelford, T. K., \& Chegeni, R. (2017). Consideration of cosmetic surgery as part of women's benefitprovisioning mate retention strategy. Frontiers in Psychology, 8, 1389. https://doi.org/10.3389/fpsyg.2017.01389.

Avalos, L., Tylka, T. L., \& Wood-Barcalow, N. (2005). The body appreciation scale: Development and psychometric evaluation. Body Image, 2(3), 285-297. https://doi.org/10.1016/j.bodyim.2005.06. 002.

Belenyesi, Gy. (2018, June, 20). Presentation of health tourism in Hungary. [Video File]. Retrieved from https://www.youtube.com/ watch?v=8PueMznYbD8

Béres, A., Czeglédi, E., \& Babusa, B. (2013). A testedzésfüggőség és a testkép vizsgálata fitneszedzést végző nők körében= Examination of exercise dependence and body image in female fitness exercisers. Mentálhigiéné és Pszichoszomatika, 14(2), 91-114. https://doi.org/ 10.1556/Mental.14.2013.2.1.

Bradshaw, H. K., Leyva, R. P., Nicolas, S. C., \& Hill, S. E. (2019). Costly female appearance-enhancement provides cues of short-term mating effort: The case of cosmetic surgery. Personality and Individual Differences, 138, 48-55. https://doi.org/10.1016/j.paid.2018.09. 019. 
Brislin, R. W. (1980). Translation and content analysis of oral and written material. In: Triandis, H. C. and Berry, J. W. (Eds.), Handbook of Cross-Cultural Psychology: Methodology, (pp. 389-444.). Boston: Allyn and Bacon.

Brown, A., Furnham, A., Glanville, L., \& Swami, V. (2007). Factors that affect the likelihood of undergoing cosmetic surgery. Aesthetic Surgery Journal, 27(5), 501-508. https://doi.org/10.1016/j.asj. 2007.06.004

Budapest Plasztikai Intézet (2019). [website] Retrieved from https:// budapestplasztika.hu/en on 14. 04. 2019.

Buss, D. M. (1989). Sex differences in human mate preferences: Evolutionary hypotheses tested in 37 cultures. Behavioral and Brain Sciences, 12(1), 1-14. https://doi.org/10.1017/ S0140525X00023992.

Calogero, R. M., Boroughs, M., \& Thompson, J. K. (2007). The impact of Western beauty ideals on the lives of women: A sociocultural perspective. In The body beautiful (pp. 259-298). London: Palgrave Macmillan. https://doi.org/10.1057/9780230596887_13.

Cash, T. F., Goldenberg-Bivens, R. B., Grasso, K. (2005). Multidimensional body-image predictors of college women's attitudes and intentions vis-á-vis cosmetic surgery. Poster presented at the Conference of the Association for Behavioral and Cognitive Therapies, Washington, DC.

Ching, B. H. H., \& Xu, J. T. (2019). Understanding cosmetic surgery consideration in Chinese adolescent girls: Contributions of materialism and sexual objectification. Body Image, 28, 6-15. https://doi. org/10.1016/j.bodyim.2018.11.001.

Crerand, C. E., Franklin, M. E., \& Sarwer, D. B. (2006). Body dysmorphic disorder and cosmetic surgery. Plastic and Reconstructive Surgery, 118(7), 167e-180e. https://doi.org/10.1097/01.prs. 0000242500.28431 .24

Czeglédi, E., Pál, E., \& Bartha, E. (2015). A megjelenéssel kapcsolatos szociokulturális attitüdök kérdőív hazai alkalmazásával szerzett tapasztalatok. Mentálhigiéné és Pszichoszomatika, 16(3), 209-230. https://doi.org/10.1556/0406.16.2015.001.

Dehghan Manshadi, Z., Kajbaf, M. B., Hamedi, S., Dehghan Manshadi, M., Nowroozi, S., \& Mollazadeh, J. (2017). Investigating the factor structure and psychometric properties of the Iranian version of the acceptance of cosmetic surgery scale. Journal Of Holistic Nursing And Midwifery, 27(3), 47-56. https://doi.org/10.18869/acadpub. hnmj.27.3.47.

Delinsky, S. S. (2005). Cosmetic surgery: A common and accepted form of self-improvement? 1. Journal of Applied Social Psychology, 35(10), 2012-2028. https://doi.org/10.1111/j.1559-1816.2005. tb02207.x.

Diener, E. D., Emmons, R. A., Larsen, R. J., \& Griffin, S. (1985). The satisfaction with life scale. Journal of Personality Assessment, 49(1), 71-75. https://doi.org/10.1207/s15327752jpa4901_13.

Dutta, S. (2008). Cosmetic surgery market: Current trends. London: Frost \& Sullivan.

Henderson-King, D., \& Brooks, K. D. (2009). Materialism, sociocultural appearance messages, and parental attitudes predict college women's attitudes about cosmetic surgery. Psychology of Women Quarterly, 33, 133-142. https://doi.org/10.1111/j.1471-6402.2008. 01480.x.

Henderson-King, D., \& Henderson-King, E. (2005). Acceptance of cosmetic surgery: Scale development and validation. Body Image, 2(2), 137-149. https://doi.org/10.1016/j.bodyim.2005.03.003.

Hu, L. T., \& Bentler, P. M. (1999). Cutoff criteria for fit indexes in covariance structure analysis: Conventional criteria versus new alternatives. Structural Equation Modeling: A Multidisciplinary Journal, 6(1), 1-55. https://doi.org/10.1080/10705519909540118.

International Society of Aesthetic Plastic Surgery (ISAPS) (2017). [website] Retrieved from https://www.isaps.org/medicalprofessionals/isaps-global-statistics/ on 14. 04. 2019.
Jovic, M., Sforza, M., Jovanovic, M., \& Jovic, M. (2017). The acceptance of cosmetic surgery scale: Confirmatory factor analyses and validation among Serbian adults. Current Psychology, 36(4), 707-718. https://doi.org/10.1007/s12144-016-9458-7.

Jung, J., \& Hwang, C. S. (2016). Associations between attitudes toward cosmetic surgery, celebrity worship, and body image among south Korean and US female college students. Fashion and Textiles, 3(1), 17. https://doi.org/10.1186/s40691-016-0069-6.

Karaca, S., Karakoç, A., Onan, N., \& Kadioğlu, H. (2017). Validity and reliability of the Turkish version of the acceptance of cosmetic surgery scale (ACSS). Journal of Psychiatric Nursing/Psikiyatri Hemsireleri Dernegi, 8(1). https://doi.org/10.14744/phd.2017. 72692.

Khoo, C. (2009). Risk reduction in cosmetic surgery. Clinical Risk, 15(6), 237-240. https://doi.org/10.1258/cr.2009.090049.

Kline, P. (1986). A handbook of test construction. London: Methuen.

Lunt, N., Smith, R. D., Exworthy, M., Green, S. T., Horsfall, D. G., \& Mannion, R. (2011). Medical Tourism: Treatments, Markets and Health System Implications: A scoping review. OECD. Retrieved from http://www.oecd.org/els/health-systems/48723982.pdf. on 14. 04. 2019.

Markey, C. N., \& Markey, P. M. (2009). Correlates of young women's interest in obtaining cosmetic surgery. Sex Roles, 61(3-4), 158-166. https://doi.org/10.1007/s11199-009-9625-5.

Martos, T., Sallay, V., Désfalvi, J., Szabó, T., \& Ittzés, A. (2014). Az Élettel való Elégedettség Skála magyar változatának (SWLS-H) pszichometriai jellemző $i=$ psychometric characteristics of the Hungarian version of the satisfaction with life scale (SWLS-H). Mentálhigiéné és Pszichoszomatika, 15(3), 289-303.

Mészáros, G. (2007). History of Hungarian Plastic Reconstructive and Aesthetic Surgery Association [online article], Retrieved from http:// www.plasztika.org.hu/info.aspx?sp=22 on 2019. 04. 14.

Nicolas, S. C., \& Welling, L. L. (2017). Women's acceptance of cosmetic surgery across the menstrual cycle. Personality and Individual Differences, 115, 99-102. https://doi.org/10.1016/j.paid.2016.04. 087.

Park, E. J. (2012. 02. 17.) Korea's plastic surgery obsession sparks concern. [online article] REUTERS, Retrieved from https://www. reuters . com/article/korea-surgery-cos meticidUSL3E8CC06K20120216 on 2019. 04. 14.

Park, L. E., Calogero, R. M., Harwin, M. J., \& DiRaddo, A. M. (2009). Predicting interest in cosmetic surgery: Interactive effects of appearance-based rejection sensitivity and negative appearance comments. Body Image, 6(3), 186-193. https://doi.org/10.1016/j. bodyim.2009.02.003.

Puts, D. (2016). Human sexual selection. Current Opinion in Psychology, 7, 28-32. https://doi.org/10.1016/j.copsyc.2015.07.011.

Rohrich, R. J. (2003). The American Society of Plastic Surgeons' procedural statistics: what they really mean. Plastic and Reconstructive Surgery, 112(5), 1389-1392. https://doi.org/10.1097/01.PRS. 0000084284.02024.3B

Rosenberg, M. (1965). Society and the adolescent self-image. Princeton: Princeton University Press.

Sallay, V., Martos, T., Földvári, M., Szabó, T., \& Ittzés, A. (2014). A Rosenberg Önértékelés Skála (RSES-H): alternatív fordítás, strukturális invariancia és validitás = Hungarian version of the Rosenberg self-esteem scale (RSES-H): An alternative translation, structural invariance, and validity. Mentálhigiéné és Pszichoszomatika, 15(3), 259-275. https://doi.org/10.1556/Mental. 15.2014.3.7.

Sarwer, D. B., Cash, T. F., Magee, L., Williams, E. F., Thompson, J. K., Roehrig, M., et al. (2005). Female college students and cosmetic surgery: An investigation of experiences, attitudes, and body image. Plastic and Reconstructive Surgery, 115(3), 931-938. https://doi. org/10.1097/01.PRS.0000153204.37065.D3. 
Sarwer, D. B., Crerand, C. E., \& Gibbons, L. M. (2007). Cosmetic surgery to enhance body shape and muscularity. In J. K. Thompson \& G. Cafri (Eds.), The muscular ideal: Psychological social, and medical perspectives (pp. 183-198). Washington, DC: American Psychological Association.

Slevec, J., \& Tiggemann, M. (2010). Attitudes toward cosmetic surgery in middle-aged women: Body image, aging anxiety, and the media. Psychology of Women Quarterly, 34(1), 65-74. https://doi.org/10. 1111/j.1471-6402.2009.01542.x.

Stefanile, C., Nerini, A., \& Matera, C. (2014). The factor structure and psychometric properties of the Italian version of the acceptance of cosmetic surgery scale. Body Image, 11(4), 370-379. https://doi.org/ 10.1016/j.bodyim.2014.06.005.

Swami, V. (2009). Body appreciation, media influence, and weight status predict consideration of cosmetic surgery among female undergraduates. Body Image, 6, 315-317. https://doi.org/10.1016/j.bodyim. 2009.07.001.

Swami, V. (2010). Translation and validation of the Malay acceptance of cosmetic surgery scale. Body Image, 7(4), 372-375. https://doi.org/ 10.1016/j.bodyim.2010.07.005.

Swami, V., \& Barron, D. (2018). Translation and validation of body image instruments: Challenges, good practice guidelines, and reporting recommendations for test adaptation. Body Image. https://doi.org/10.1016/j.bodyim.2018.08.014.

Swami, V., \& Mammadova, A. (2012). Associations between consideration of cosmetic surgery, perfectionism dimensions, appearance schemas, relationship satisfaction, excessive reassurance-seeking, and love styles. Individual Differences Research, 10(2), 81-94.

Swami, V., Arteche, A., Chamorro-Premuzic, T., Furnham, A., Stieger, S., Haubner, T., \& Voracek, M. (2008a). Looking good: Factors affecting the likelihood of having cosmetic surgery. European Journal of Plastic Surgery, 30(5), 211-218. https://doi.org/10. 1007/s00238-007-0185-z.

Swami, V., Campana, A. N. N. B., \& Coles, R. (2012a). Acceptance of cosmetic surgery among British female university students: Are there ethnic differences? European Psychologist, 17(1), 55-62. https://doi.org/10.1027/1016-9040/a000049.

Swami, V., Campana, A. N. N. B., Ferreira, L., Barrett, S., Harris, A. S., \& Fernandes, M. D. C. G. C. (2011a). The acceptance of cosmetic surgery scale: Initial examination of its factor structure and correlates among Brazilian adults. Body Image, 8(2), 179-185. https:// doi.org/10.1016/j.bodyim.2011.01.001.

Swami, V., Chamorro-Premuzic, T., Bridges, S., \& Furnham, A. (2009a). Acceptance of cosmetic surgery: Personality and individual difference predictors. Body Image, 6(1), 7-13. https://doi.org/10.1016/j. bodyim.2008.09.004.

Swami, V., Henderson, G., Custance, D., \& Tovée, M. J. (2011b). A cross-cultural investigation of men's judgments of female body weight in Britain and Indonesia. Journal of Cross-Cultural Psychology, 42(1), 140-145. https://doi.org/10.1177/ 0022022110383319 .

Swami, V., Hwang, C. S., \& Jung, J. (2012b). Factor structure and correlates of the acceptance of cosmetic surgery scale among south Korean university students. Aesthetic Surgery Journal, 32(2), 220 229. https://doi.org/10.1177/1090820X11431577.

Swami, V., Salem, N., Furnham, A., \& Tovée, M. J. (2008b). Initial examination of the validity and reliability of the female photographic figure rating scale for body image assessment. Personality and Individual Differences, 44(8), 1752-1761. https://doi.org/10.1016/j. paid.2008.02.002.

Swami, V., Taylor, R., \& Carvalho, C. (2009b). Acceptance of cosmetic surgery and celebrity worship: Evidence of associations among female undergraduates. Personality and Individual Differences, 47(8), 869-872. https://doi.org/10.1016/j.paid.2009.07.006.

Swami, V., Taylor, R., \& Carvalho, C. (2011c). Body dissatisfaction assessed by the photographic figure rating scale is associated with sociocultural, personality, and media influences. Scandinavian Journal of Psychology, 52(1), 57-63. https://doi.org/10.1111/j. 1467-9450.2010.00836.x.

Thompson, J. K., Van Den Berg, P., Roehrig, M., Guarda, A. S., \& Heinberg, L. J. (2004). The sociocultural attitudes towards appearance scale-3 (SATAQ-3): Development and validation. International Journal of Eating Disorders, 35(3), 293-304. https:// doi.org/10.1002/eat.10257.

Publisher's Note Springer Nature remains neutral with regard to jurisdictional claims in published maps and institutional affiliations. 